\title{
UNSPOKEN HINTS E MEMÓRIA COMO MONTAGEM EM NOVELAS GRÁFICAS: O CASO D'A TRAVESSIA
}

\author{
UNSPOKEN HINTS AND MEMORY AS MONTAGE \\ IN GRAPHIC NOVELS: THE CASE OF A TRAVESSIA
}

UNSPOKEN HINTS Y MEMORIA COMO MONTAJE EN NOVELAS GRÁFICAS: EL CASO DE

A TRAVESSIA

LUANA BAROSSI ${ }^{1}$

${ }^{1}$ Doutora em Estudos Comparados de Literaturas de Língua Portuguesa pela Universidade de São Paulo. 
RESUMO: O cineasta Sergei Eisenstein desenvolve os conceitos de montagem e de unspoken hints em sua coletânea de textos "Laocöon", conceitos esses que vão além do campo cinematográfico. A teoria de Eisenstein potencializa a leitura de obras literárias, em seu sentido amplo, mas parece particularmente significativa quando tratamos de obras com suporte ou recurso gráfico para a composição diegética, como as histórias em quadrinhos e, especialmente, as novelas gráficas. O presente artigo dispóe dessa teoria para uma proposta de leitura de novelas gráficas, tratando, mais especificamente, da obra A Travessia, de Camila Torrano.

ABSTRACT: The filmmaker Sergei Eisenstein develops concepts that go beyond the film field in his collection of texts "Laocöon": the concepts of montage and unspoken hints. Eisenstein's theory potentiates the reading of literary works in its broad sense, but it seems particularly significant when we deal with works with graphic support for its diegetic composition, such as comic books and, especially, graphic novels. This article makes use of this theory to propose a reading of graphic novels, dealing more specifically with the work $A$ Travessia, by Camila Torrano.

RESUMEN: El cineasta Sergei Eisenstein desarrolla los conceptos de montaje y de unspoken hints en su antología de textos "Laocöon", tales conceptos extrapolan el campo cinematográfico. La teoría de Eisenstein potencializa la lectura de obras literarias, en sentido amplio, y parece particularmente significativa cuando tratamos de obras con soporte o recurso gráfico para la constitución diegética, como las historietas y, en especial, las novelas gráficas. El presente artículo se utiliza de esa teoría para una propuesta de lectura de novelas gráficas, y trata, de modo más específico, de la obra $A$ Travessia, de Camila Torrano.

PALAVRAS-CHAVE: Novela gráfica; Unspoken hints; Montagem; Sergei Eisenstein; Camila Torrano

IKEYWORDS: Graphic novel; Unspoken hints; Montage; Sergei Eisenstein; Camila Torrano.

PALABRAS CLAVE: Novela gráfica; Unspoken hints; Montaje; Sergei Eisenstein; Camila Torrano

$\cos$

Minha alma penada,
antiga e pesada
naufraga navios
degola amadas
E desce, ilesa
na próxima parada. ${ }^{2}$

(Janaina Tokitaka)

\footnotetext{
${ }^{2}$ Poema que consta no cartão/marcador componente do livro, escrito por Janaína Tokitaka, organizadora da coletânea da qual A travessia faz parte.
} 
O presente artigo tem como intuito discutir como alguns aspectos da teoria de Sergei Eisenstein, sobre a montagem como procedimento fundador do pensamento humano, podem ser particularmente relevantes para a leitura de novelas gráficas, em geral, mas tratando particularmente da obra $A$ travessia, de Camila Torrano.

As novelas gráficas, como outras produções quadrinizadas, têm como aspecto constitutivo a presença da linguagem verbal e não-verbal. Esta última, embora tenha características próprias, dependendo da perspectiva de análise, dialoga com diversas técnicas cinematográficas (CIRNE, 2004; ECO, 1970). Cirne (2004) especifica que Umberto Eco recorre ao jargão crítico do cinema em Apocalípticos e integrados para a análise das produçôes literárias quadrinizadas. Christian Metz, no entanto, em "A significação no cinema", (2012), opóe-se à abordagem de Eco, pois buscava uma especificidade cinematográfica, ou seja, procurava determinar o que diferenciaria, por uma perspectiva semiótica, o cinema dos demais procedimentos artísticos. Enquanto Eco aborda os quadrinhos pela via teórica do cinema, Metz procura especificar qual é a linguagem própria desse último, evitando sua conexão com as demais formas de arte. Já Sergei Eisenstein (2010) parte de um olhar distinto aos de Eco e Metz ao propor que a montagem, tipicamente relacionada à técnica cinematográfica, é um procedimento básico do pensamento humano, de forma geral, de maneira que qualquer ato de criação artística ou até psíquica passa pela ideia de montagem. Nesse sentido, é importante diferenciar os conceitos de montagem e decupagem. Enquanto a decupagem seria um procedimento técnico, geralmente deliberado, para a constituição das obras (cinematográficas ou gráficas), a montagem estaria mais relacionada à própria concepção da obra, partindo da memória, de imagens e sugestôes que se sobrepóem para a constituição de um todo. Esse "todo" não traz necessariamente a ideia de plenitude, mas de sugestóes que se unem em uma composição, ainda que fragmentada.

Embora não fale especificamente de produçôes quadrinizadas, o conceito de montagem, nos termos de Eisenstein, pretende-se abrangente, com o sentido de pensamento-montagem. O autor propõe que o cinema é um Urphänomen ${ }^{3}$ da habilidade do conhecimento. Diz que

\footnotetext{
${ }^{3}$ Em tradução livre, "fenômeno originário". Ou seja, de acordo com o autor, a montagem é elemento constitutivo do pensamento.
} 
o princípio do cinema é algo que surgiu do mais profundo das culturas humanas. Ele analisa esse processo em vários autores, entre eles Scriabin e Shakespeare, apontando em suas obras o pensamento-montagem.

Eisenstein propóe, então, por sua teoria bastante heterodoxa, a compreensão da literatura também como montagem, uma vez que essa seria constitutiva do pensamento humano. A característica básica de uma sequência de montagem é a sugestáo, ou seja, ela tem elementos que, juntos, são capazes de evocar um sentido da totalidade de uma concepção. As unspoken hints ${ }^{4}$ são parte desse processo, atuando como sugestóes que compóem as características básicas da sequência de montagem na obra de arte. No caso do cinema, as unspoken hints aparecem por meio de estratégias como o close-up, que perceberemos também presentes na novela gráfica $A$ travessia.

A memória como montagem também é importante para compreender a teoria de Eisenstein (2010), pois o autor alega que um fenômeno característico do comportamento é que a natureza humana é incapaz de comunicar um evento com total objetividade, em especial quando tal evento pressupóe um envolvimento emocional (Pathos). O exemplo do cineasta é o conto detetivesco "The crime of Captain Gahagan", de Chesterton. Nesse conto, um homem é acusado de um crime, pois havia supostamente dado três explicaçôes distintas a três mulheres diferentes sobre a noite do crime. Na sobreposição das descrições das mulheres, chega-se à conclusão de que o álibi era válido, uma vez que ele havia contado a mesma história às três mulheres, que, por sua vez, haviam extraído do relato sua própria "montagem". O ponto a provar aqui é que a memória capta imagens e as monta numa sucessão de eventos que, por vezes, pode ser até contraditória, em especial quando há envolvimento emocional.

Tais consideraçóes podem fazer-nos conceber a própria presença do insólito como montagem na novela gráfica $A$ Travessia, escrita e ilustrada pela artista plástica Camila Torrano. Embar-

\footnotetext{
${ }^{4}$ Por não encontrar uma tradução ao português do texto de Eisenstein em questão, optamos por manter a expressão em inglês no decorrer do texto, pois a versão utilizada de "Laocoön" está em inglês. Poderíamos adotar a tradução "dica não dita” ou "dica inaudita”, mas ambas as possibilidades pareceram-nos alterar consideravelmente o sentido original de "unspoken hint".
} 
cados em um coffin ship $p^{5}$ foragidos da Irlanda da década de 1840, o que fornece uma contextualização histórica real ao plano diegético, Dr. Doyle e a senhorita Sarah O’Reilly iniciam a história com uma apreensiva discussão sobre a demora para chegar ao seu destino: a cidade de Nova Iorque. No entanto, antes de o leitor ser apresentado aos personagens principais, algumas sugestóes são evocadas. Um apreciador atento pode perceber, logo na arte da capa do livro, que traz uma âncora (no entanto, uma âncora sem corda) sobreposta a uma imagem de mar revolto, trabalhado em uma estilística de reentrâncias e saliências, uma remissão à conhecida obra $A$ Grande Onda ${ }^{6}$ (figura 1), de Katsushika Hokusai.

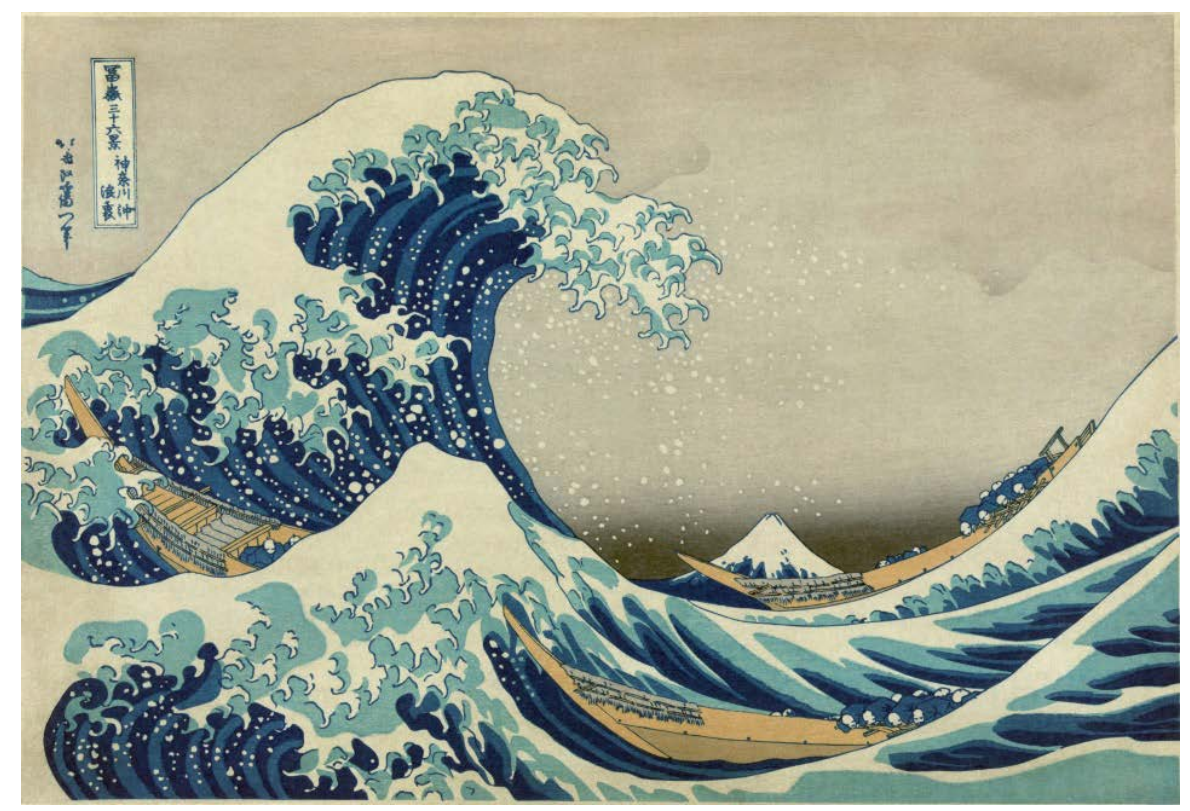

Figura 1

A Grande Onda, de Hokusai, parece prestes a engolir os três barcos, que no lugar de figuras humanas simples, apresenta sombras de seres humanoides encurvados. O tipo das em-

\footnotetext{
${ }^{5}$ Navio que já fez muitas viagens e está muito velho. Foi o principal meio de transporte dos imigrantes irlandeses que fugiam da crise gerada pela Grande Fome. Os navios não ofereciam segurança e os recursos como água e comida eram escassos (TORRANO, 2012, p.7). "Coffin", traduzido ao português, é caixão. Um "navio-caixão" carrega no seu título a sugestão do destino de seus integrantes.

${ }^{6}$ Obra de 1830, trata-se de uma "Ukiyo-e", gravura japonesa típica dos séculos XVII, XVIII e XIX, em geral na forma de xilogravuras. O título (Kanagawa oki nami ura), geralmente traduzido ao português como "A grande onda de Kanagawa", tem o sentido de "sob uma onda fora de Kanagawa". A gravura tem as dimensões de $25 \mathrm{~cm} \times 37 \mathrm{~cm}$.
} 
barcaçóes é o oshiokuri-bune, tradicional barco de pesca japonês que carrega peixes vivos de uma cidade a outra. $\mathrm{O}$ fato de ter a representação desse tipo de embarcação na gravura permite que muitos analisem a obra considerando que seus integrantes sejam pescadores. Embora as análises da gravura de Hokusai primem por afirmar que se trata de uma onda prestes a engolir os três barcos, as feiçôes insólitas e os corpos encurvados dos ocupantes sugerem apreciações que ultrapassam a simples vulnerabilidade humana com relação ao mar. Parece que esses ocupantes do oshiokuri-bune são tão assustadores quanto a onda prestes a engoli-los, na medida que produzem um efeito de estranhamento no apreciador. Eles não parecem apenas homens agarrados aos remos pelo medo da imensidão da onda. $\mathrm{O}$ apreciador, por sua vez, está presente na obra, pois o ponto de vista, ao contrário de outras gravuras que compóem as 36 vistas do Monte Fuji ${ }^{7}$ , é baixo, como se estivéssemos, ao apreciar a obra, próximos aos barcos, ou dentro de um deles. Devemos temer a grande onda ou a própria existência aparentemente não humana dos integrantes dos barcos? Esses integrantes são tão humanos quanto nós ou somos nós tão estranhos quanto eles?

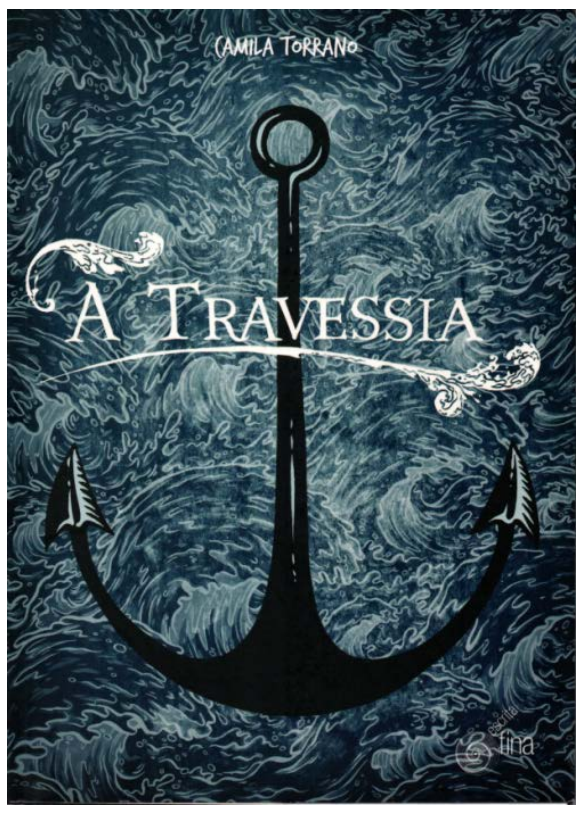

Figura 2
Apesar de não apresentar apenas uma onda, mas um mar revolto, a forma das inúmeras ondulaçóes na ilustração de capa (Figura 2) do livro de Torrano tem uma característica próxima à do artista japonês. Os barcos, no entanto, não aparecem nessa ilustração, mas trarão, no decorrer da história, seres também temíveis. A âncora, que sugeriria alguma segurança para a embarcação, uma vez que permite uma parada temporária, transformando o barco, de certa forma, em uma ilha flutuante, tem sua simbologia alterada por aparecer sem corda ou corrente. Uma âncora sem corda é um objeto pesado prestes a se perder na profundidade das águas. Esses elementos da ilustração da capa fornecem algumas unspoken hints para que o leitor/apreciador da obra execute sua montagem.

\footnotetext{
7 Conjunto de obras de Hokusai do qual “A grande onda...” faz parte, que, na verdade, é composto por 46 imagens.
} 
Além da capa e suas possíveis referências, há um prólogo de ambientação com a contextualização histórica do período da Grande Fome da Irlanda, decorrente, entre outros fatores, da peste que devastou plantaçóes de batatas. Muitos irlandeses embarcavam em coffin ships em direção à América do Norte ${ }^{8}$. A precariedade dessas embarcações acabou resultando na construção mítica de inúmeras histórias fantásticas de travessia oceânica. Muitos desses navios, ou apenas seus integrantes, não chegavam ao destino. A contextualização histórica traz ao plano diegético dois elementos cruciais: 1) a porção de verossimilhança que será, na sequência, sobreposta pelo aspecto insólito e inquietante (unheimlich) e 2) o percepto da obra, ou seja, a ambientação, imprescindível para a apreciação estética da novela gráfica.

O fato de a nota de abertura trazer uma contextualização "real" ao plano diegético é um recurso que amplifica o aspecto estranho da presença de elementos insólitos, de maneira que não pretende apenas estabelecer um pacto ficcional com o leitor fixado na noção de verossimilhança (esse mundo é o mesmo que o nosso), mas estabelecer uma potencialização do efeito de estranhamento, quando os elementos que escapam a essa perspectiva mundana se apresentarem na história e se contrapuserem aos primeiros. O conceito freudiano de unhemilich é interessante para compreender o estranhamento, nesse caso, pela particularidade de propor a noção de algo que é concomitantemente familiar e não familiar: algum elemento aparentemente novo, estranho, que traz à tona algum aspecto que estava oculto no inconsciente.

Além disso, o prefácio da obra de Torrano propicia uma ambientação espaço-temporal, sugerindo que, embora o mundo seja o mesmo que o nosso, isso se passou em outro tempo e em outro lugar. Essa ambientação, se por um lado pode ter finalidade didática, ao explicitar o contexto histórico e a existência, na época, desse tipo de viagem no gênero de embarcação em questáo, por outro, estabelece também um percepto. Em outras palavras: estabelece uma sugestão de como seria se encontrar nessa situação de fuga: o pathos da experiência das condiçôes precárias de navegação. A montagem do espaço, se pensada pelas relaçóes de força, direciona a um percepto dos acontecimentos, que deixam, eventualmente, de existir como eram. Esse percepto também funciona como

\footnotetext{
${ }^{8}$ Essa temática é trabalhada em diversas obras literárias, como Alias Grace, de Margaret Atwood, recentemente adaptada para a série de televisão homônima.
} 
uma sugestáo no processo de montagem mas, dessa vez, já estabelece o estranhamento pelo deslocamento espaço-temporal, com foco nas condiçóes de sobrevida daqueles navegantes.

O procedimento de close up como unspoken hint da teoria de Eisenstein parece ser também conditio sine qua non para a montagem na obra de Torrano. Uma ilustração do coffin ship em perspectiva fronte-lateral, dessa vez no mar calmo, é a sequência ao prólogo (figura 3). A paisagem aparentemente pacífica, apesar das nuvens que começam a se carregar no céu e do reflexo solar no oceano, que sugere um pôr de sol, trazem, em princípio, uma contraposição aos elementos evocados no prólogo, sugerindo, no entanto, a iminência da tempestade e da escuridão. $\mathrm{O}$ close se dá nas páginas seguintes, quando a aproximação a uma das janelas de madeira velha e um corte da cena para esse pedaço da embarcação sugere a aproximação da câmera, da perspectiva e o leitor é levado, no centro da ilustração, ao primeiro baláo de diálogo, cujo conteúdo, embora contenha uma palavra positiva (bem), é seguido de reticências, o que produz uma modalização do discurso e traz um sentido de inquietação à expressão (bem...). A aproximação do foco penetra o espaço interno no primeiro quadro da página seguinte, mostrando a silhueta das duas personagens, Sarah, acabrunhada, curvada, preocupada; e Doyle, ereto, alegre, segurando uma garrafa.

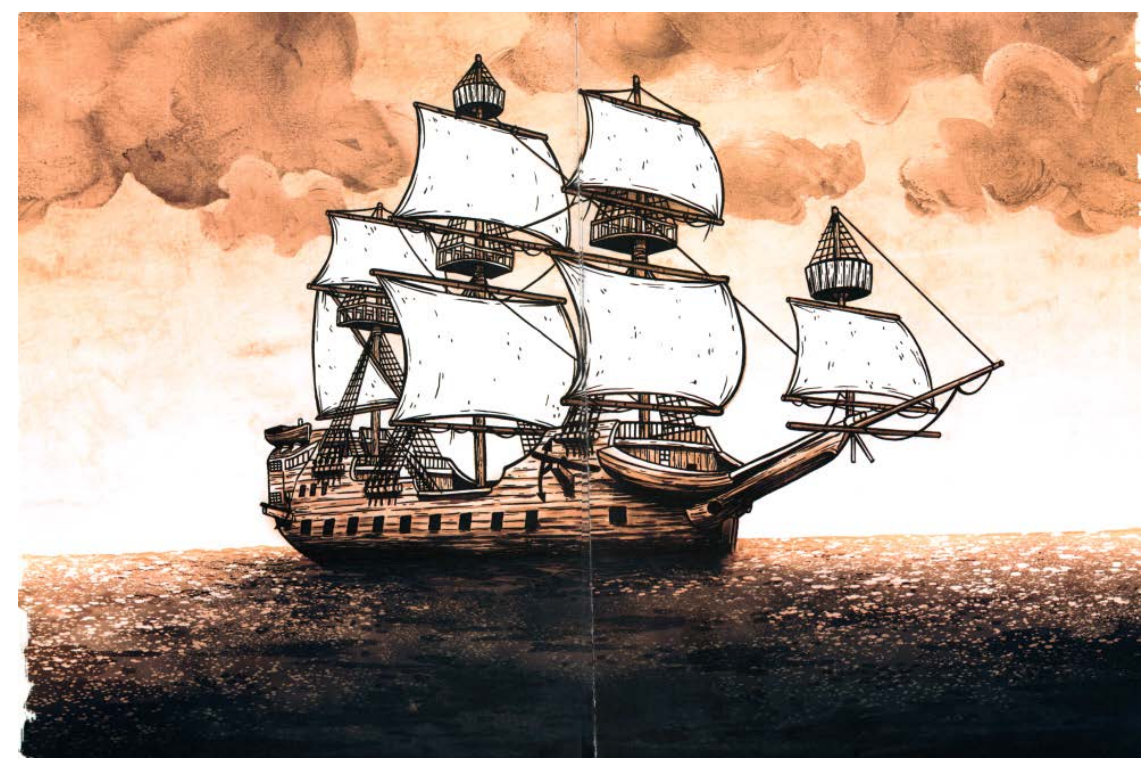

Figura 3 
Nos quadros seguintes, vemos as feiçóes apreensivas da moça contrapostas ao sorriso e feição otimista do médico, enquanto Sarah bebe o último gole do líquido da garrafa e a encara como se aquele objeto significasse algo. Eles discutem sobre a demora para chegar a Nova Iorque. Então, mais um close up, aparentemente sem sentido, incide sobre a mão de

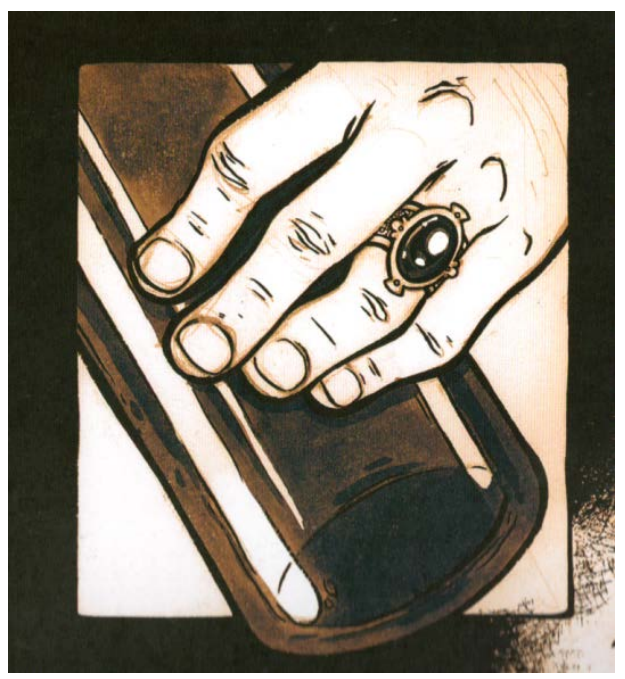

Figura 4
Doyle, que segura a garrafa vazia e ostenta um anel no dedo anelar da mão esquerda, provavelmente relativo à sua formatura no curso de medicina, costume da época (figura 4). Embora pareça desnecessário nesse momento, a fixação nessa imagem será importante para a compreensão do andamento da história. Outra unspoken hint diz respeito à ilustração da página $15^{9}$, quando Sarah discorre sobre os perigos da travessia para as Américas, de acordo com as narrativas dos padres: "Das pessoas que sobreviveram aos ataques, muitas perderam o juízo e poucas chegaram à terra em seu pleno estado mental" (TORRANO, 2012, p.15). Entretanto, a unspoken hint aqui não consiste nos dados oferecidos pela linguagem verbal, ou seja, na afirmação da moça, mas na imagem que se espalha pelos quadros das duas páginas: uma vertente de seres em um movimento fluido como o da onda de Hokusai que deriva da cabeça de Sarah (figura 5).

\footnotetext{
${ }^{9}$ A novela gráfica não apresenta numeração de páginas. A numeração feita aqui para referência foi feita pela autora do artigo.
} 

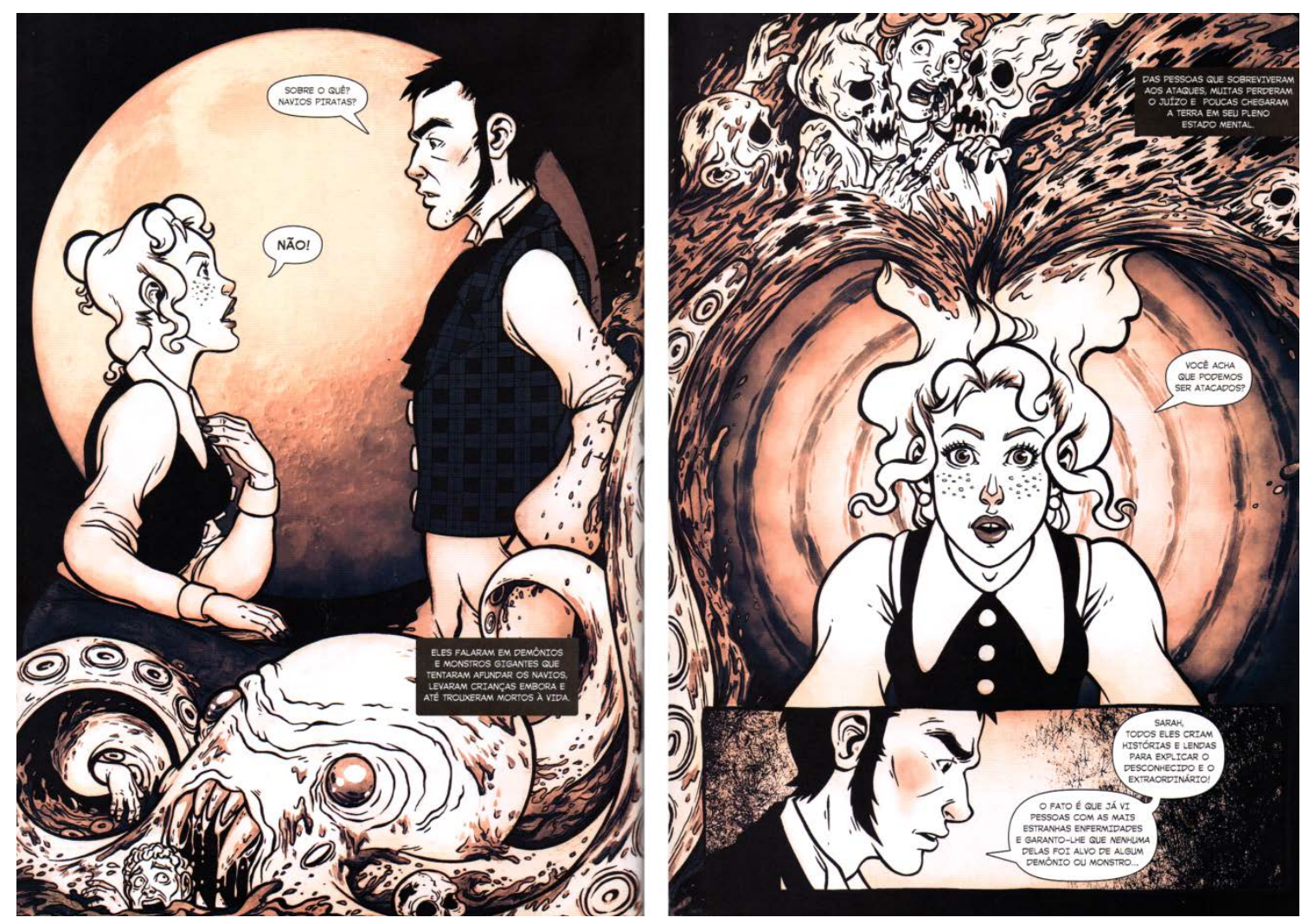

Figura 5

Polvos monstruosos e gigantescos agarram humanos com feiçôes assustadas, caveiras atordoam faces apavoradas, tudo em meio a uma onda impelida como uma explosão da cabeça da personagem. A pergunta de Sarah, nesse momento: "você acha que podemos ser atacados?" (TORRANO, 2012, p.15) parece se contrapor à própria origem dos monstros. Isso porque se a simbologia de sair da cabeça de quem conta a história poderia sugerir meramente o fato de corresponder à imaginação da personagem, nesse caso específico parece ter um sentido mais abrangente: os monstros simbolicamente fluem de dentro dela própria, pois o estranho reside no próprio corpo de quem o invoca do inconsciente.

Dr. Doyle, por sua vez, detentor do dispositivo científico, procura sempre uma explicaçáo racional para os acontecimentos: "Sarah, todos eles criam histórias e lendas para explicar o desconhecido e o extraordinário! O fato é que já vi pessoas com as mais estranhas enfermidades e garanto-lhe que nenhuma delas foi alvo de algum demônio ou monstro". (TORRANO, 2012, p.15). As estranhas enfermidades aludidas pelo médico têm relação com a constituição da própria noção de loucura. 
Doyle ainda reflete que o mar reserva surpresas como tempestades, mas que as criaturas fantásticas pertenciam aos livros. Essa afirmação aparece em um balão de diálogo sobreposto à figura do mar revolto, no mesmo estilo que o da capa, associada anteriormente, nesse artigo, à gravura de Hokusai. Lembremos, no entanto, que na leitura feita aqui da obra do artista japonês, propusemos elementos que ultrapassam a mera vulnerabilidade humana com relação à imensidão oceânica. Essa proposição reaparecerá também na novela gráfica, contrariando a afirmação de Doyle.

Para tranquilizar a companheira de viagem, Doyle questiona o capitáo James sobre a previsão de chegada. Com sua luneta e uma feição pouco amigável, James observa o horizonte e prevê a chegada em 14 dias, se o tempo assim permitir. Nesse momento, outro integrante do navio escorrega e despenca com a face voltada para o chão e a perna de pau lançada para o ar. Doyle se oferece para cuidar dos machucados do homem de face enrugada e de poucos dentes, mas recebe como resposta algumas dicas sobre seu futuro: "Você não vai chegar lá, então não adianta cuidar do machucado agora se você não estará aqui depois. Na verdade, você vai chegar ao seu destino, vai continuar sua carreira - mas não será você mesmo”. (TORRANO, 2012, p. 21-22 - negrito no original). O que significaria não ser mais ele mesmo? Como poderia chegar ao destino, mas não ser a mesma pessoa? Ao perceber que o tripulante de perna de pau parecia falar mais do que deveria, Ulrich, outro personagem, interrompe a conversa e convoca Dr. Doyle e senhorita Sarah para jantarem na cabine do capitão James. Doyle e Sarah saem do convés e o foco incide no rosto dos dois homens que lá permaneciam, quadro seguido por um corte no olhar e na feição de Ulrich. Esse close up, em seu macabro olhar de perfil, é montado em um quadro sobreposto a outro maior, uma perspectiva posterior do navio, em noite de lua cheia, denunciando seu nome grafado na popa (figura 6). 


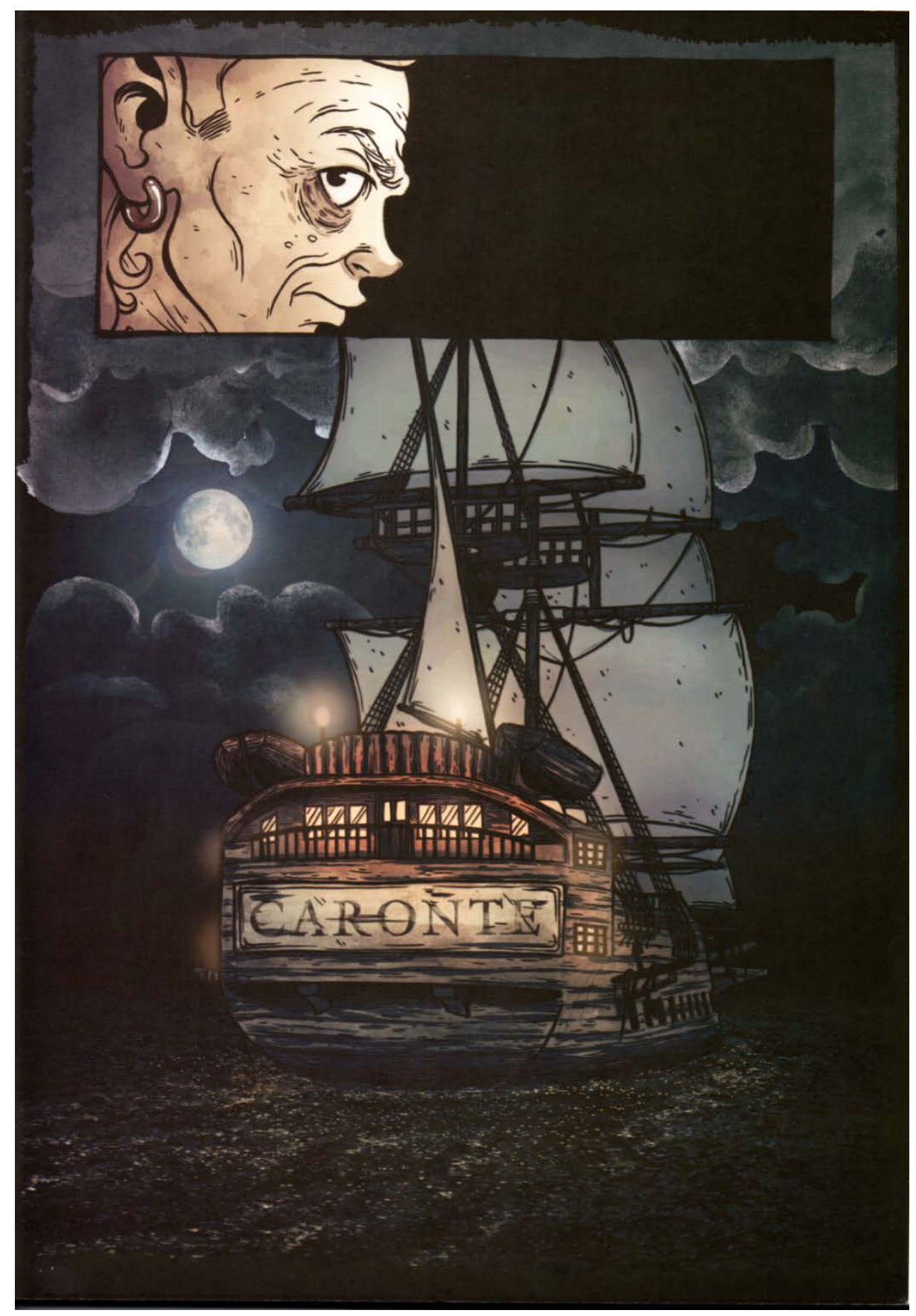

Figura 6

Esse é um momento crucial à obra, pois a referência ao barqueiro da mitologia greco-romana intensifica o percepto fúnebre da travessia. Caronte, que aparece em muitas obras da tradição clássica, era o responsável pelo transporte das almas dos mortos pelos rios Estige e Aqueronte para o mundo inferior. No entanto, ele só atravessava aqueles que pagavam e que haviam sido propriamente enterrados, motivo pelo qual se criou, à época, o hábito de inserir 
uma moeda na boca dos cadáveres para que pudessem ter sua passagem efetivada. Caronte é bem descrito na Eneida, de Virgílio, como um velho magro e horrendo, porém forte:

Daqui parte o caminho do Aqueronte,

Que em funda bolha férvida voragem,

E ao Cocito arremessa areia e lodo.

Fero esquálido arrais guarda estas águas,

Caronte hediondo, cuja barba espessa

Branqueia inculta, os lumes lhe chamejam,

E aos ombros suja capa em nó lhe pende:

Puxando à vara, ou mareando as velas,

Em cimba enfarruscada os vultos passa;

Velho, mas como um deus, robusto e verde.

(VIRGÍLIO, Livro VI, p, 137, versos 304-314)

Aqueles que não pagam pela travessia, "Cem anos volteando ansiosos vagam” (VIRGÍlLO, Livro VI, verso 339). Ao evocar o barqueiro de Aqueronte, Torrano estabelece uma noção de travessia que extrapola o mero transporte intercontinental. Nesse ponto, a história passa a adotar outro procedimento de montagem. Dessa vez, a sobreposição de cenas marca uma temporalidade paralela. Na primeira cena, dois tripulantes caçam um albatroz e Ulrich oferece um presente embrulhado em um saquinho para o médico. Com sua face otimista, Doyle agradece. Na segunda cena, Sarah desce aos poróes para procurar seu xale e ouve um grunhido. Ao procurar a fonte do barulho, visualiza no escuro uma silhueta humana com olhos estranhos. Retoma-se a cena um, com um close no albatroz sendo atravessado por uma bala, enquanto Doyle, irritado com o acontecimento, não dá tanta atenção ao embrulho em suas mãos, abrindo-o sem cerimônia. A imagem da página seguinte traz o médico com uma cara assustada e um close no presente recebido, lançado ao chão no impulso provocado pelo susto: uma língua humana cortada. Antes que tivesse tempo de questionar o tripulante que o presenteara, Doyle ouve um grito no porão e as cenas se justapóem, com uma pausa bem no meio da história, nas páginas centrais do livro. Duas páginas negras e uma vela caída no chão. 
Ao procurar pela companheira de viagem, Doyle encontra Sarah ao lado do personagem sem perna, amarrado, com a boca ensanguentada e os olhos brancos, sem íris ou pupilas. Mais um close, dessa vez na boca do tripulante, denuncia que sua língua fora cortada (figura 7). Indignado com a situação, Doyle propóe que Sarah ofereça uma bebida ao homem para que sua dor fosse reduzida e vai questionar o capitão: "Capitão James, paguei a passagem conforme combinado e o senhor nos trata como se fôssemos um dos ratos!! E seus tripulantes são animais..." (TORRANO, 2012, p. 48). Tendo pagado ao barqueiro - em retomada à referência de Caronte - eles deveriam ter a travessia efetivada. Capitão James, por sua vez, ameaça Doyle e o obriga a entrar com Sarah na cabine.

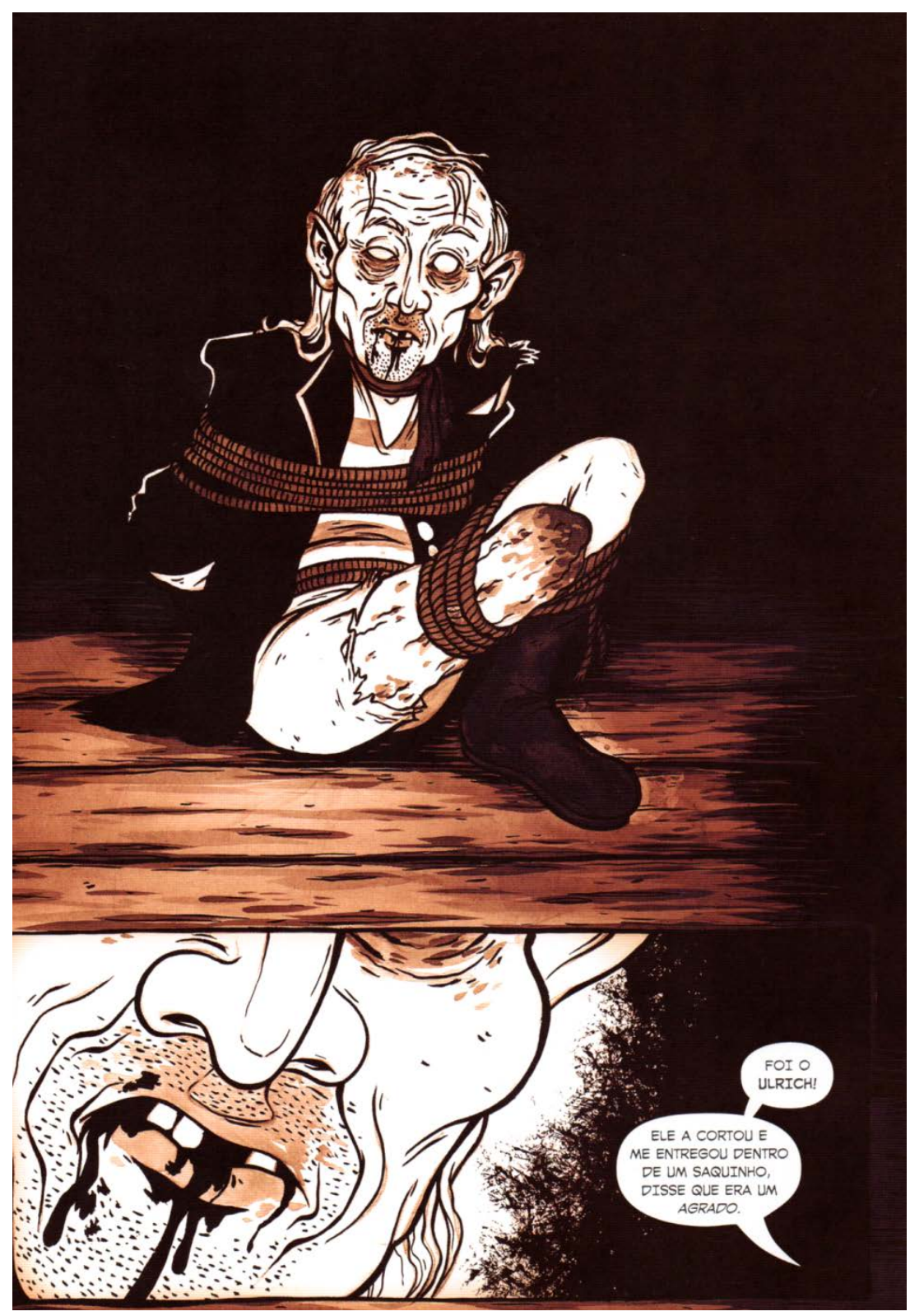

Figura 7 
A imagem do mar revolto é evocada mais uma vez, agora sob uma tempestade. Presos na cabine, discutindo sobre os estranhos acontecimentos, ouvem a tempestade se aproximar. Doyle insiste em manter sua perspectiva racional sobre os acontecimentos, mesmo que os elementos façam emergir o pathos insólito: "Sarah, não me venha com suas crendices idiotas!! Os doentes têm visões e elas são frutos de suas enfermidades!" (TORRANO, 2012, p. 54). A discussão é interrompida pela representação de um barulho e pela imagem de uma luz forte incidindo em um redemoinho gigantesco. A luz atinge o navio e o close no casal denuncia que estão presos na cabine.

Nesse momento, uma bifurcação acontece e eles visualizam outro barco. A aproximação de uma figura humana com olhos brancos resulta em um close de Doyle. No entanto, um Doyle sem íris ou pupilas. A ausência dos olhos como os conhecemos provoca um estranhamento anteriormente evocado na figura da personagem perneta. No quadro inferior, o close incide na imagem apavorada de Doyle e Sarah (Figura 8). 


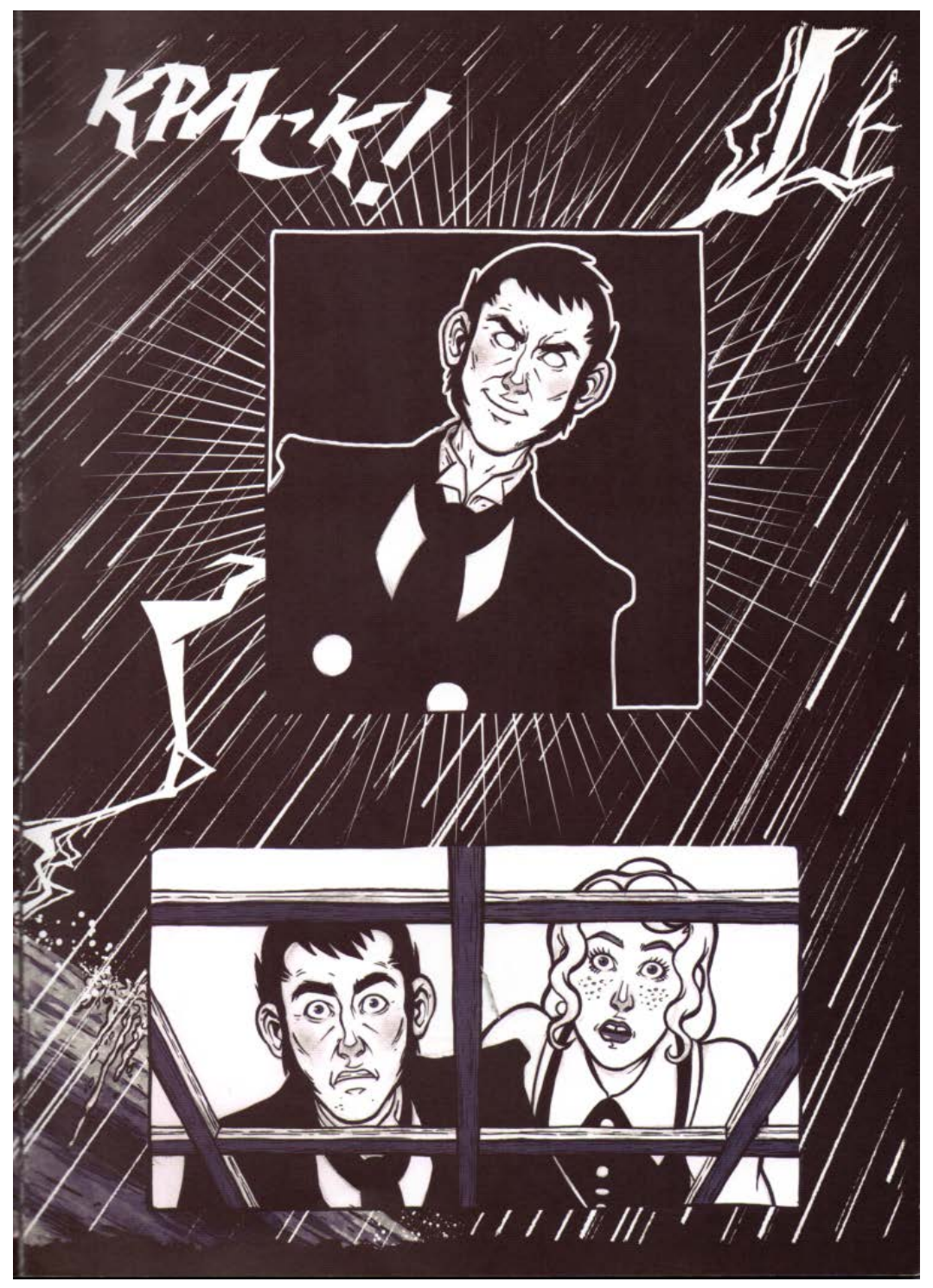

Figura 8

O Capitão James, dessa vez com olhos brancos, entra na cabine com um facão em punho. Ao ser questionado sobre o que significava aquilo, o capitão ironiza com a racionalidade de Doyle (figura 9). 


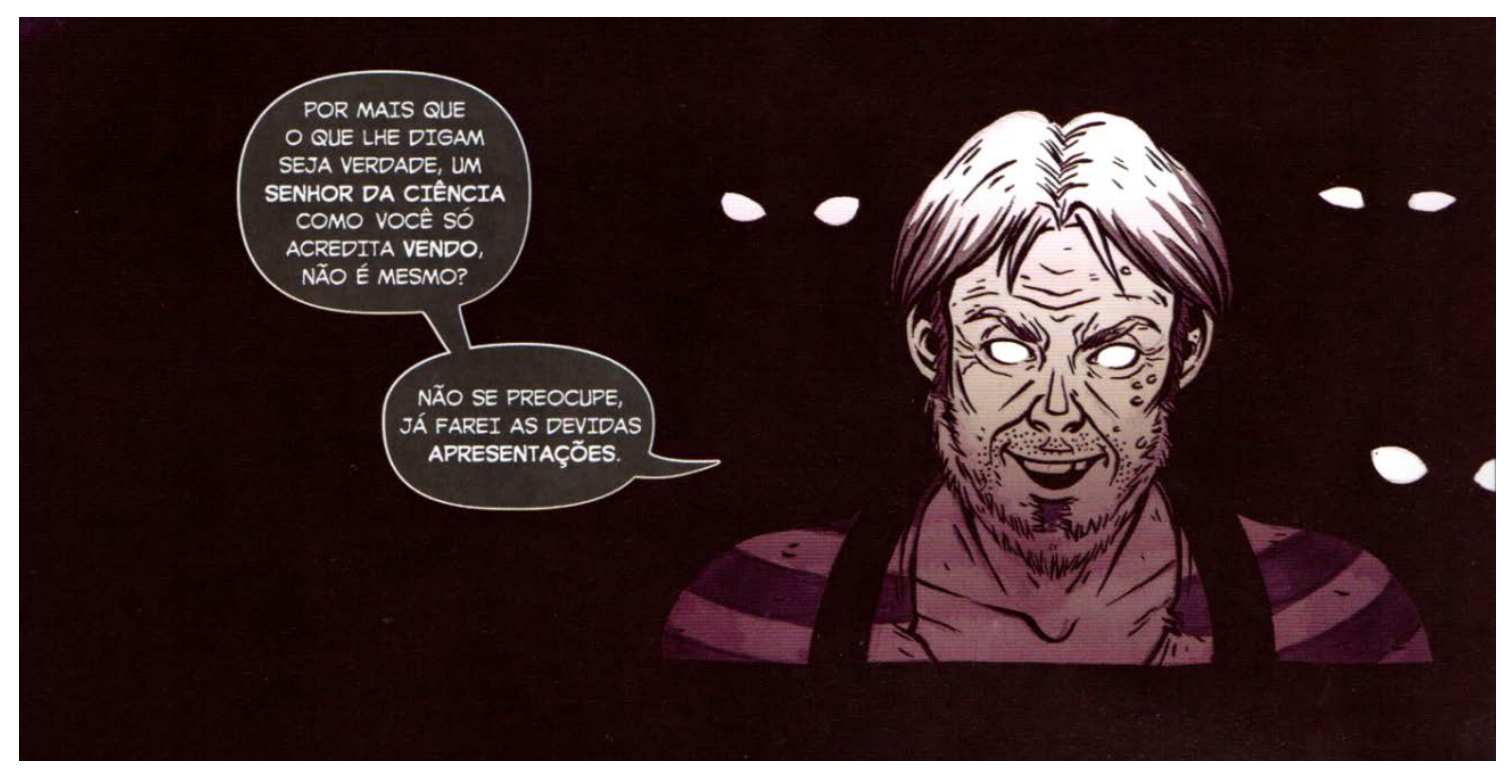

Figura 9

O capitão de olhos brancos lança o facão ao duplo de Doyle. A imagem espelhada na página mostra de um lado o casal "original”, com feiçóes assustadas; do outro, seus duplos de olhos brancos, sorrindo, enquanto a versão outra de Doyle segura o facão lançado pelo capitão. A explicação oferecida na sequência pelo tripulante Ulrich pode parecer excessiva: Todos os seres tinham um duplo no início do mundo, um doppelgänger. Como esses duplos discordavam dos deuses, decidiram que apenas a versão fraca habitaria o mundo. Agora, os duplos decidiram caçar o correspondente frágil e lançá-lo na escuridão antes habitada pela versão mais poderosa.

Embora as versôes "originais" de Doyle e Sarah sejam carregadas à força para o convés e recebam a explicação cosmogônica de Ulrich para a existência dos duplos, a bifurcação sugere que questionemos, inclusive, a explicação do tripulante, que se torna, nesse momento, um narrador não confiável. A explicação da existência de um duplo de cada ser legado ao mundo da escuridão, duplo esse que aproveitada a fenda aberta na travessia para tomar o lugar de sua versão "humana", reduz a potência da história. No entanto, tal explicação se dá pela necessidade do médico de se prender ao mundo racional tal qual ele o concebe, de forma que, mesmo um acontecimento insólito necessitaria de uma explicação plausível, ainda que baseada em explicações fantásticas. 
A bifurcação assume a presença de mundos possíveis, a coexistência de todas as possibilidades imanentes em cada instante, como proposto por Deleuze e Guattari (1992). Se tomarmos a noção do percepto da obra, com seu constante ritornelo à obsessão do médico pelo dispositivo científico, percebemos como a negação à variação impede que se perceba outras possibilidades de existência:

Com efeito, a dúvida comporta momentos que não são as espécies de um gênero, mas as fases de uma variação: dúvida sensível, científica, obsessiva [...]. O mesmo vale para os tipos de ser, coisa ou substância: o ser infinito, o ser pensante finito, o ser extenso. É de se observar que, neste último caso, o conceito do eu não retém senão a segunda fase do ser, e deixa de fora o resto da variação. Mas esse é precisamente o sinal de que o conceito se fecha como totalidade fragmentária com "eu sou uma coisa pensante": não se passará a outras fases do ser senão por pontes-encruzilhadas que levam a outros conceitos. (DELEUZE e GUATTARI, 1992, p. 39).

O conceito eisensteiniano de montagem reaparece aqui, na própria produção do artigo, nessa intersecção com o pensamento de Deleuze e Guattari. A bifurcação busca novas formas por atualizar, de sorte que apenas pela coexistência temporária de dois mundos possíveis no momento da encruzilhada (dois navios, dois Doyles, duas Sarahs) é que o ser finito deixa de se atualizar, dando espaço ao outro de si. O mesmo estava tão impregnado na existência única e na racionalidade científica, que sua existência se limitava a uma linearidade sem variação. Daí a necessidade do duplo tomar seu lugar, mantendo, no entanto, uma lembrança do que era. O mundo outro a ser atualizado finalmente ganha olhos. O primeiro navio é então engolido pelo redemoinho, enquanto sua atualização segue viagem. Assim como os seres evocados na gravura de Hokusai aparecem supranumerários, as personagens da novela gráfica também o são. Enquanto os seres de Hokusai estão sensíveis a todas as possibilidades imanentes àquele instante (a onda), as personagens de Torrano são forçadas a assumir um mundo outro, por se prenderem apenas a uma possibilidade. 


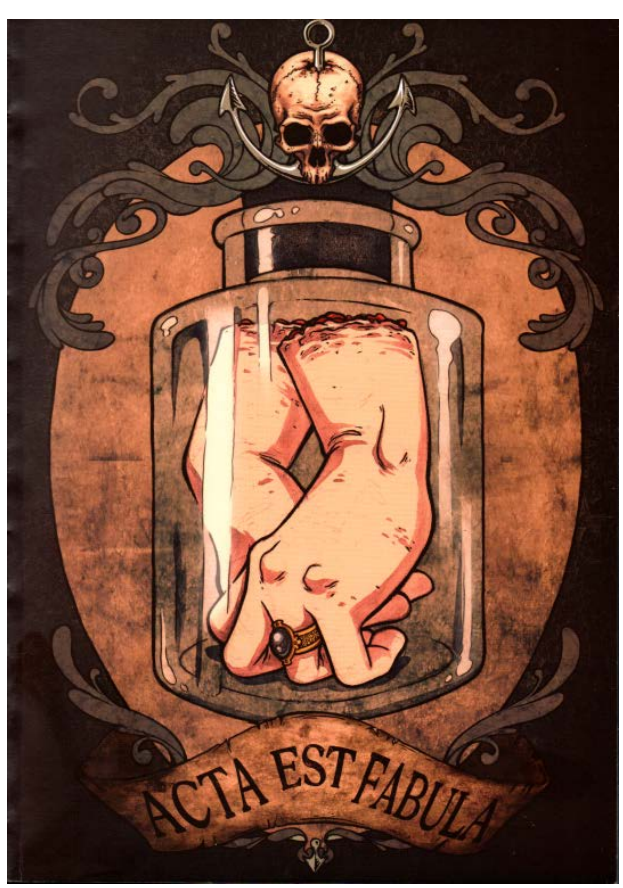

Figura 10

O corte para a chegada ao destino em Nova Iorque traz Sarah se apresentando ao funcionário da alfândega como dama de companhia da família Doyle, enquanto o médico é questionado pelo funcionário sobre o que carregava: garrafa com duas mãos em seu interior, uma delas com um anel de formatura, uma lembrança do outro que foi (figura 10), aludida, no começo da narrativa, no close up da mão, naquele momento do lado de fora do utensílio.

A loucura evocada no começo da obra oferece também chaves de leitura para esse final, "acta est fabula". Por se contrapor à perspectiva essencialmente racionalista do Doyle "original", um discurso nomeado como "louco" pelo dispositivo científico é produtivo, principalmente se tomarmos as concepçôes de Foucault. Lembremos que as histórias de padres anunciavam que os tripulantes dos coffin ships não chegavam ao seu destino em plenas faculdades mentais. Paralelamente à sobreposição temporal dos eventos e cenas da travessia, os escapes de olhar, presentes nas imagens de personagens sem íris ou pupilas, para outras possibilidades de existência, sugerem que a leitura pelo viés do fantástico, como um aspecto ilusório, uma vez que escaparia à norma da verossimilhança de uma perspectiva realista, seja desfeita pela mudança de perspectiva. Por escapar da norma interna da verossimilhança, aquela que entende a obra de maneira funcionalista, ou seja, em função da realidade racionalista dada, a loucura abriria espaço para aquilo que não poderia ser explicado, pois, como propóe Foucault, "enquanto o homem racional e sábio só percebe desse saber algumas figuras fragmentárias - e por isso mesmo, mais inquietantes -, o Louco o carrega inteiro em uma atmosfera intacta: essa bola de cristal, que para todos está vazia, a seus olhos está cheia de um saber invisível”. (FOUCAULT, 1008, p. 20-21).

Uma leitura fechada em si também impede a possibilidade de atualização, de forma que este artigo náo se propóe a responder todas as questóes suscitadas pela obra, nem servir 
como um todo definitivo, apenas oferecer alguns insights de como a teoria de Eisenstein, da montagem como princípio do pensamento, pode auxiliar uma leitura produtiva da novela gráfica de Camila Torrano. 


\section{REFERÊNCIAS}

CIRNE, Moacy. Quadrinhos, memória e realidade textual. In: Anais do XXVII Congresso da Intercom, Porto Alegre, 2004.

DELEUZE, G; GUATTARI, F. O que é a filosofia? São Paulo: Ed. 34 Letras, 1992.

ECO, Umberto. Apocalipticos e integrados. São Paulo: Perspectiva, 1970.

EISENSTEIN, Sergei. “Laocoön”. In: Towards a theory of montage. London/New York:

I. B. Tauris, 2010.

FOUCAULT, Michel. História da loucura na Idade Clássica. São Paulo: Perspectiva, 2008.

FREUD, Sigmund. O estranho. In: Obras Completas, volume XVII - Uma neurose infantil e outros trabalhos (1917-1919). Rio de Janeiro: Imago, 1976.

HOKUSAI, Katsushika (1830). Kanagawa-oki nami ura. [Ukiyo-e (xilogravura)] Sumida: The Sumida Hokusai Museum (domínio público).

METZ, Christian. A significação no cinema. São Paulo: Perspectiva, 2012.

TORRANO, Camila. A travessia. Rio de Janeiro: Escrita Fina, 2012.

VIRGÍLIO. Eneida. Tradução de Manuel Odorico Mendes (1799-1864). Versão em epub Centaur Editions, 2013. 